\title{
Antibacterial Activity of Endophytic Fungi Isolated from Pometia pinnata J. R. Forst \& G. Forst against Escherichia coli
}

\author{
D Prasetyani ${ }^{1}, \mathrm{R}$ Setyaningsih ${ }^{1 *}$, A Susilowati $^{1}$
}

\author{
${ }^{1}$ Department of Biology, Faculty of Mathematics and Natural Sciences, Sebelas Maret University, Jl. Ir. Sutami \\ 36 A, Kentingan, Surakarta, 57126, Indonesia \\ *Corresponding author: ratna_s@staff.uns.ac.id
}

\begin{abstract}
The emerging of antimicrobial resistance become a global concern, encouraging researchers to find out alternative antimicrobial compounds. Endophytic fungi associated with medicinal plants become promising sources because of their ability to produce medical bioactive. This study aimed at bioprospecting fungal endophytes from an ethnobotanical medicinal plant, Pometia pinnata J. R. Forst \& G Forst for their antimicrobial activity. Endophytic fungi isolated from leaf, stem, and root aseptically. Ten selected endophytes were cultured and then extracted using ethyl acetate. Screening antibacterial activity of ethyl acetate extract carried out by paper disk diffusion assay against Escherichia coli ATCC 25922. TLC-bioautography assay was used to study the type of secondary metabolite which has antibacterial activity. Identification of endophytic fungi based on morphology and ITS sequence using ITS1 and ITS4 primers. The result showed that two isolates have antibacterial activity but only one isolate exhibits strong antibacterial activity with a diameter of inhibition zone $21 \mathrm{~mm}$. The isolate was identified as Aspergillus minisclerotigenes with $100 \%$ identity of the ITS sequence using BLAST software on NCBI. TLC assay indicated that ethyl acetate extract of $A$. minisclerotigenes contains alkaloids, phenols, flavonoids, and terpenoids while TLC bioautography showed that its phenolic compound appeared antibacterial activity.
\end{abstract}

Key words: Antibacterial Activity, Endophytic, Pometia pinnata, Escherichia coli

\section{INTRODUCTION}

Antibiotic resistance has become a global problem. As a result of antibiotic resistance, there has been an increase in mortality and health care costs. The increasing of bacterial resistance to antibiotics requires the search for new antibiotic compounds that are more effective. Even the Infectious Disease Society of America (IDSA) has launched a program to develop 10 new antibiotic classes that are safer and more effective until 2020[1]. Antibiotic resistance in Escherichia coli isolated from dogs and cats is an increasing problem; $51 \%$ of 376 isolates collected from sick dogs and cats in the United States in 2005 showed resistance to at least one drug, and $29 \%$ of the 376 isolates were multiple drug resistant[2].

Endophytic fungi are a potential source of new antibiotics because of the diversity of bioactive compounds they produce. The ability of endophytic fungi to synthesize bioactive compounds is related to the ability of their host plants to synthesize these compounds. This is due to the coevolution of genetic transfer from the host[3].

One of ethnobotanical plant that is widely used as a medicine is matoa (Pometia pinnata J. R. Forst $\&$ G. Forst). Matoa used to cure diarrhea, stomach trouble, cough, fever, constipation, and diaper[4]. Because of the efficacy in the medical field that is owned by matoa plants, there is a need for research 
on the exploration and identification of endophytic fungi of matoa plants which have antibacterial activity.

\section{MATERIALS AND METHODS}

\subsection{Sample Collection and Isolation of Endhopytic Fungi}

Plant samples including leaf, stem, and root were collected from a healthy Pometia pinnata J. R. Forst \& $\mathrm{G}$ Forst tree in Karangpandan, Karanganyar, Jawa Tengah, Indonesia. Each sample was first rinsed under running tap water to remove soil and other debris, then surface sterilization was done to eliminate epiphytic microorganism. For surface sterilization and fungal isolation, the methods described by Marcellano et al.[5] was followed with modification. The samples were immersed in $70 \%$ alcohol for 3 minutes and shaken slowly, continued by sodium hypochlorite $(5.5 \% \mathrm{NaOCl})$ for 3 minutes, and then washed thrice with sterile distilled water for 3 minutes each sample. The last rinsed water was cultured on isolation media to confirm that surface sterilization was done successfully. Successfully sterilization shows the absence of microbes in the isolation media. Surface-sterilized samples were cut using a sterile blade into $0.25-1 \mathrm{~cm}^{2}$ pieces and aseptically transferred to a petri dish containing potato dextrose agar (PDA) medium supplemented with chloramphenicol $50 \mathrm{mg} / \mathrm{L}$. Plates were incubated at $27 \pm 3^{\circ} \mathrm{C}$ until fungal growth was initiated. Only fungal hyphae emerging from the samples were transferred to new PDA plates through hyphal tipping to obtain a pure culture.

\subsection{Cultivation and Secondary Metabolite Extraction}

Cultivation and secondary metabolite extraction from fungal endophytes following the methodology described by Sharma et al.[6] with minor modification. Each fungus was grown in $100 \mathrm{~mL}$ potato dextrose broth (PDB) and incubated at $28^{\circ} \mathrm{C}$ with periodical shaking $90 \mathrm{rpm}$ for 14 days using shaker incubator. After the incubation period, mycelia and culture broth was separated using Whatman filter paper. Then, $100 \mathrm{~mL}$ ethyl acetate (EtOAc) was used to extract secondary metabolites from broth culture and mycelia. After 24 hours, the ethyl acetate was separated from the mycelia using Whatman filter paper. Afterward, ethyl acetate extract was separated from the broth using a separation funnel. Concentrated extracts were obtained by using a vacuum rotary evaporator at $40^{\circ} \mathrm{C}$ and then kept at $4^{\circ} \mathrm{C}$.

\subsection{Antimicrobial Activity Assay}

The antimicrobial activity of ethyl acetate extract was carried out using paper disk diffusion assay against human pathogen Escherichia coli ATCC 25922 based on NCCLS[7]. The bacteria obtained from Microbiology Laboratorium, Faculty of Medicine, Universitas Sebelas Maret. The bacteria were sub-cultured in Nutrient Agar (NA) medium for 24 hours before testing. The bacterial suspension were standardized using $0.5 \mathrm{McFarland}$ Standard $\left(1.5 \times 10^{8} \mathrm{CFU} / \mathrm{mL}\right)$. The bacteria were inoculated on a surface of Mueller-Hinton agar (MHA).

A sterilized $6 \mathrm{~mm}$ paper disk $\left(\mathrm{Oxoid}^{\mathrm{TM}}\right)$, saturated with $30 \mu \mathrm{L}$ extract was placed on the agar plate surface containing bacteria. A paper disk saturated with ethyl acetate was used as a negative control, while another paper disk saturated with $30 \mu \mathrm{L}$ Chloramphenicol $(20 \mathrm{mg} / \mathrm{mL})$ was used as a positive control. All plates were incubated at $37^{\circ} \mathrm{C}$ for 24 hours. The ethyl acetate extract which has antimicrobial activity will produce a zone of inhibition that can be measured.

\subsection{TLC-Bioautography Assay}

Thin Layer Chromatography (TLC) bioautography was conducted to determine the type of secondary metabolite which has antibacterial activity. TLC was performed using silica gel plate GF254 was used as stationary phase and dichloromethane: methanol (9:1) as a mobile phase. The ethyl acetate extract of fungal endophytes was spotted to the plate. Afterward, the TLC plate was developed in a chamber previously saturated with the mobile phase and waited until the mobile phase reaches the solvent front. The developed plate was dried. For detection of bioactive compound, the developed plate sprayed with Dragendroff for alkaloid detection with positive result exhibit orange to red colour, Liebermann Burchard for terpenoid and sterol detection positive result for terpenoid produce pink colour while steroid is green, $\mathrm{FeCl}_{3}$ for phenol detection with positive result produce red, blue or green colour and ammonia steam for a flavonoid detection positive result will exhibit yellow colour. Following that, the $R f$ value from the spots was measured[8].

The bioautography assay was conducted based on Yin et al.[8] with minor modification. The inoculum of test bacteria was prepared standardized using $0.5 \mathrm{McF}$ arland Standard $\left(1.5 \times 10^{8} \mathrm{CFU} / \mathrm{mL}\right.$ ) and inoculated on the surface of MHA. The developed TLC plate was placed on the MHA previously seeded with bacteria for 30 minutes to allow diffusion of bioactive compounds. Afterward, the TLC plate was removed, and the agar was 
incubated at $37^{\circ} \mathrm{C}$ for 24 hours. The spots that produce a zone of inhibition were located by comparing $R f$ value from the TLC assay.

\subsection{Morphological and Molecular Identification of Endophytic Fungi}

Endophytic fungi with strongest antimicrobial activity were identified morphologically by directly observing the fungal endophytes' growth on the media and through microscopic examination using slide culture method. The macroscopic character used for identification were surface colour and reverse colour, while microscopic character including hypha and sporulating structure such as conidia and conidiophore. The fungus was also identified by ITS rDNA sequence analysis. The genomic DNA of endophytic fungi was extracted from fungal mycelium using Quick-DNA ${ }^{\mathrm{TM}}$ Fungal/Bacterial Miniprep Kit according to the extraction kit's protocol. ITS region of rDNA was amplified in a polymerase chain reaction (PCR) using the genomic DNA as a template and primers ITS1: TCCGT AGGTGAACCTGCGG and ITS4: TCCTCCGCTTGATATGC[9]. Amplified DNA was subjected to DNA sequencing and the DNA sequence obtained was compared with already existing DNA sequences in NCBI GenBank (http://blast.ncbi.nlm.gov/).

\section{RESULTS AND DISCUSSION}

\subsection{Endophytic Fungi Isolated from $P$. pinnata}

Based on visible morphological differences when grown on PDA medium, totally 29 endophytic fungi were isolated from several parts of $P$. pinnata (Table 1.)

Table 1. Endhopytic Fungi Isolated from $P$. pinnata

\begin{tabular}{ccc}
\hline No & Part of Plant & Total Isolates \\
\hline 1 & Leaf & 8 \\
2 & Stem & 10 \\
3 & Root & 11 \\
\hline Total & & 29 \\
\hline
\end{tabular}

Fungal endophytes occurrence depends on the host plant. Plants growing in areas of great biodiversity including $P$. pinnata have the prospect of housing endophytes with great biodiversity. An ethnobotanical plant such as $P$. pinnata supposed to have endophytic fungi that can produce unique bioactive compound[10].

\subsection{Antimicrobial Activity}

Ten isolates with the fastest growth rate after 7 days of incubation among the total 29 isolates were selected. Isolate with a high growth rate become a prospective bioactive producer due to effectiveness and efficiency in bioactive production. Secondary metabolites from ten selected isolates were extracted using ethyl acetate. According to Garcia et al.[11]., ethyl acetate was chosen because it was the best solvent to extract secondary metabolites from endophytic fungi. Besides that, ethyl acetate was able to extract phenolic compounds with low molecular weight and polyphenol compounds with high molecular weight[12]. Ethyl acetate extract of endophytic fungi showed promising result by exhibiting antimicrobial activity with zones of inhibition ranging from $12.1 \mathrm{~mm}$ to $21 \mathrm{~mm}$ (Table 2). 
Table 2. Antibacterial activity isolated from $P$. pinnata

\begin{tabular}{rlc}
\hline No & \multicolumn{1}{c}{ Isolate Code } & $\begin{array}{c}\text { Zone of inhibition } \\
(\mathrm{mm})\end{array}$ \\
\hline 1 & AM4 & - \\
2 & BM1B & - \\
3 & AM6 & - \\
4 & BM6 & - \\
5 & AM71 & 12.1 \\
6 & BMB & - \\
7 & DM2 & 21 \\
8 & DM1 & - \\
9 & BM1 & - \\
10 & DMF1 & - \\
& Ethyl acetate & - \\
& Chloramphenicol & 26.3 \\
\hline
\end{tabular}

Paper disk diffusion assay is a common method to evaluate antimicrobial activity. This method offers many advantages such as simplicity, low cost, the ability to test an enormous number of microorganisms and antimicrobial agents, and the result is easy to interpret[13]. Among of 10 endophytic fungi isolates tested, DM2 showed the highest antimicrobial activity with a zone of inhibition $21 \mathrm{~mm}$ (Figure 1).

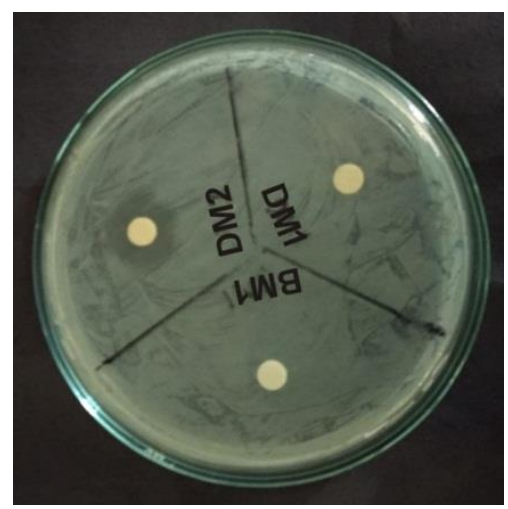

Figure 1. Zone of inhibition of ethyl acetate extract DM2

According to Davis and Stout, extract which can produce a zone of inhibition more than $20 \mathrm{~mm}$ considered to have a very strong ability to inhibit bacterial growth[14]. The activity exhibited by endophytic fungi from $P$. pinnata was presumably due to the antibacterial activity reported in previous studies using its fruit peels and bark $[15,16]$. This finding shows that the extract of DM2 could be a potential resource of the antimicrobial compound.

\subsection{TLC-Bioautography Assay}

DM2 which has the strongest antibacterial activity was evaluated to study the antimicrobial compounds present in its ethyl acetate extract. TLC assay was performed to separate the bioactive compound and identify the secondary metabolites. TLC assay showed that ethyl acetate extract of DM2 contains alkaloids, phenols, flavonoids, and terpenoids indicated by the presence of spots showing the positive result after being sprayed by each reagent at different $\mathrm{Rf}$ value (Figure 2a). 


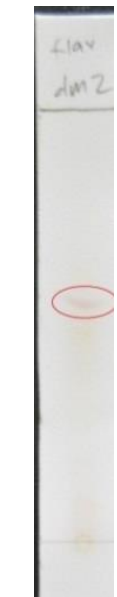

Flavonoid Rf 0.5

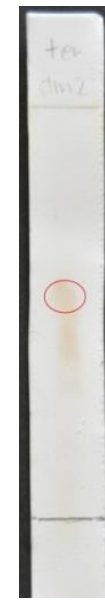

Terpenoid Rf 0.6

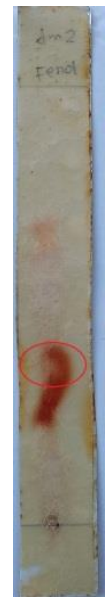

Phenolic Rf 0.38

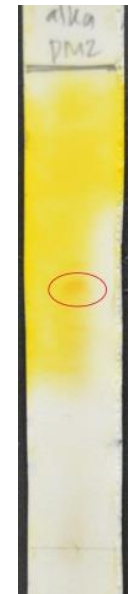

Alkaloid 0.64

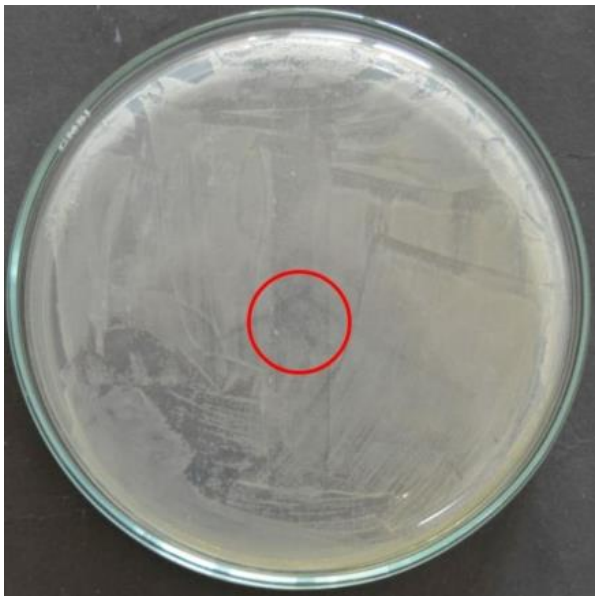

Zone of inhibition on TLC-bioautography

(b)

Figure 2. TLC-bioautography of DM2 extract. Chromatograms of ethyl acetate extract of DM2(a); Zone of inhibition at $R f$ value 0.38

The bioautography assay showed that the phenolic compound present in the extract exhibits antimicrobial activity against Escherichia coli ATCC 25922 by producing a zone of inhibition with $\mathrm{Rf}$ value 0.38 (Figure 2b). Antibacterial mechanism of the phenolic compound was disrupting cell membrane and inhibit DNA gyrase[17].

Isolate which has the highest antibacterial activity was identified morphologically. DM2 colonies on PDA after 7 days at $27 \pm 3^{\circ} \mathrm{C}$ appeared greyish green on the surface and orange on the reverse (Figure 4 a-b). Microscopically, isolate showed septate hypha, aspergillum with biseriate conidial head, and hyaline conidiophore (Figure 4c). These characters lead to Aspergillus minisclerotigenes[18].

\subsection{Morphological and Molecular Identities of Endophytic Fungi}

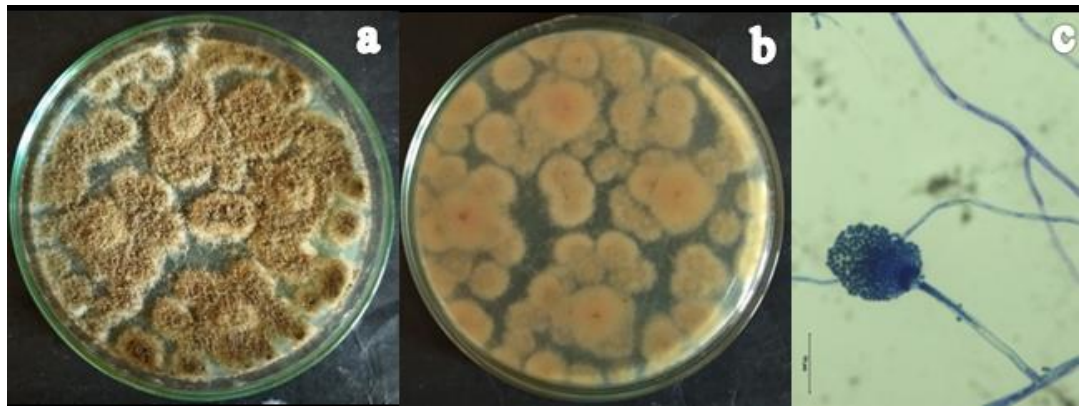

Figure 3. Morphological characters DM2. Surface color (a); Reverse color (b); Aspergillum of DM2 at 400x magnification (c)

Molecular identification based on the ITS rDNA region used confirms the identity of the fungi. ITS region was recommended as the universal barcode for fungi because the ITS region has the highest probability to identify fungal species due to the existence of high variable region dan PCR performance success rate $[19,20]$. The amplicon of ITS rDNA region fungi was analyzed using electrophoresis on $1 \%$ agarose gel. Figure 5 showed that the amplicon size was $\pm 572 \mathrm{bp}$. 


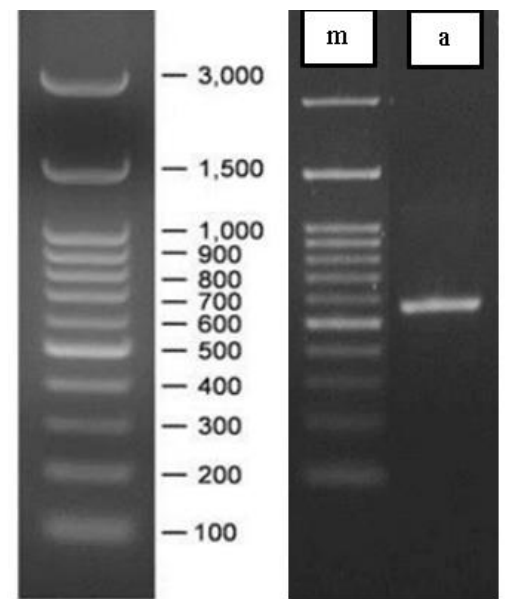

Figure 4. Electrophoregram ITS rDNA region of DM2. Marker DNA ladder 100 bp (m), amplicon \pm 572 bp (a).

Based on BLAST-N analysis, isolate DM2 which exhibits the highest antimicrobial activity against $E$. coli has a $100 \%$ similarity with the Gene
Bank database (Table 3) which indicates similarity at a species level.

Table 3. Molecular identity of DM2

\begin{tabular}{cccccc}
\hline No & Isolate Code & Closest Species Identity & Query Cover & Identity & Accession Number \\
\hline 1 & DM2 & Aspergillus minisclerotigenes & $99 \%$ & $100 \%$ & MG662408.1 \\
\hline
\end{tabular}

Molecular identification confirms that isolate DM2 is Aspergillus minisclerotigenes. Fungi from Aspergillus genera previously reported as endophytic fungi and able to produce antimicrobial compounds [21, 22]. Rani et al.[21] reported that ethyl acetate extract of Aspergillus nomius and Aspergillus oryzae isolated from Calotropis procera have antimicrobial activity against Salmonella typhi, Shigella lexneri, and Serratia marcescens. Thorati and Mishra[22] reported that the crude extract of Aspergillus niger isolated from the stilt roots of Rhizophora apiculata able to inhibit five human bacterial pathogens.

\section{CONCLUSION}

This study demonstrated that endophytic fungi isolated from Pometia pinnata J. R. Forst\&G. Forst exhibits antibacterial activity. The isolate DM2 identified as Aspergillus minisclerotigenes has antimicrobial activity against $E$. coli due to its phenolic content. This finding leads to the utilization of this fungus as an alternative source of the antimicrobial compound.

\section{REFERENCES}

[1] Infectious Disease Society of America (ISDA) 2010 Clinical Infectious Diseases 50 pp1081-1083

[2] Sykes J E 2014 Canine and Feline Infectious Disease (Missouri: Elsevier)

[3] Tan R X and Zou W X. 2001 Nat. Prod. Rep. 18 pp 448-459
[4] WHO. 1998. Medicinal Plants in The South Pasific.Manila: WHO

[5] Marcellano J P, Collanto A S, Fuentes R G 2017 Pharmacogn J 93 pp 405-409

[6] Sharma D, Pramanik A, Agarwal P K 2016 3 Biotech 6210 pp 1-14

[7] National Committee for Clinical Laboratory Standards (NCCLS) 2004 Performance Standards for Antimicrobial Disk and Dilution Susceptibility Testing; Fourteenth Informational Supplement NCCLS documents M100-S14 (Way Pennsylvania USA.)

[8] Yin O C J, Ibrahim D, Lee C C 2015 Malays. j. med. biol. res. 23 pp 262-272.

[9] White T J, Bruns T, Lee S and Taylor J 1990. Amplification and direct sequencing of fungal ribosomal RNA genes for phylogenetics in PCR protocols: a guide to methods and applications (New York: Academic Press) pp 315-322

[10] Strobel G and Daisy B 2003. Microbiology And Molecular Biology Reviews 674 pp 491-502

[11] Garcia A, Rhoden S A, Bernardi-Wenzel J, Orlandelli R C, Azevedo J L, and Pamphile J A 2012 Journal of Applied Pharmaceutical Science 210 pp 35-40

[12] Scholz E and Rimpler H 1989 Planta Medica 55 pp 379-384

[13] Balouiri M, Sadiki M, Ibnsouda S K 2016 
Journal of Pharmaceutical Analysis 6 pp 7179

[14] Davis W W and Stout T R 1971 Microbiology 22 pp 659-665

[15] Faustina F C and Santoso F $2014 J$. Pascapanen $\mathbf{1 1} 2$ pp 80 - 88

[16] Ngajow M, Abidjulu J, Kamu V S 2013 Jurnal Mipa Unsrat Online 22 pp 128-132

[17] Rempe C S, Burris K P, Lenaghan SC, and Steward Jr N 2017 Frontiers in Microbiology. 8422 pp 1-12

[18] Pildain M B, Frisvard J C, Vaamonde G, Cabral D, Varga J, and Robert A S 2008 International Journal of Systematic and Evolutionary Microbiology 58 pp 725-735

[19] Mahmoud AGY and Zaher E H F 2015 Adv Genet Eng 42 pp 1-2

[20] Fajarningsih N D 2016 Squalen Bull. of Mar. and Fish. Postharvest and Biotech 112 pp 37-44

[21] Rani R, Sharma D, Chaturvedi M, and Yadav J P 2017 Clin Microbiol 63 pp 1-6

[22] Thorati M and Mishra J K 2017 Journal of Pharmacognosy and Phytochemistry $65 \mathrm{pp}$ 1635-1638 